\title{
ONE SESSION BILATERAL CAROTID STENTING - EXPERIENCE FROM SLOVAKIAN CENTER
}

\author{
Nosal $\mathrm{V}^{1}$, Zelenak $\mathrm{K}^{2}$, Sivak $\mathrm{S}^{1}$, Michalik $\mathrm{J}^{1}$, Kantorova $\mathrm{E}^{1}$, Pecova $\mathrm{R}^{3}$, Kurca $\mathrm{E}^{1}$
}

${ }^{1}$ Neurology Clinic, Jessenius Faculty of Medicine in Martin, Comenius University in Bratislava, Slovak Republic ${ }^{2}$ Radiology Clinic, Jessenius Faculty of Medicine in Martin, Comenius University in Bratislava, Slovak Republic ${ }^{3}$ Institute of Pathological Physiology, Jessenius Faculty of Medicine in Martin, Comenius University in Bratislava, Slovak Republic

A b s t r a t

Objectives: Bilateral carotid artery stenting (BCAS) in one session is relatively rare procedure. However, clear recommendations still do not exist. The aim of our study was to analyze efficacy and safety of the BCAS performed by single operator in our center.

Material and Methods: A retrospective analysis of 95 carotid angioplasty with stent implantation (CAS) patients performed in our center, totally 9 patients ( 8 males and 1 female, age 59-83, average 69) was identified where simultaneous BCAS was performed. All patients had bilateral hemodynamic significant stenosis $(\geq 70 \%)$, and all patients had symptomatic stenosis.

Results: Only 1 patient was without any complication. The most frequent complications were arterial hypotension. However, duration of stay on the Intensive Care Unit, or hospitalisation was not prolonged. From serious complications we noticed one case of periprocedural filter occlusion and one patient died 30 days after procedure. No other serious complications were in the BCAS group noticed.

Conclusion: Because of limited data it is not possible to make any clear conclusions or recommendations from the results of our study. Our data show that probably BCAS appears to be safe and effective way in the treatment of bilateral carotid artery stenosis in high-risk population.

Key words: bilateral CAS, bilateral carotid stenosis, stroke prevention

\section{INTRODUCTION}

Ischemic stroke is the third leading cause of death and the first leading cause of disability of adults in the industrialized countries (WHO 1999). Atherosclerotic disease of the cerebral arteries is one of the most important etiopathogenetic causes of the cerebral infarction (Mathur et al. 1998; Henry et al. 2005; Diehm et al. 2008). Atherosclerosis may be involved in the development of cerebral infarction by several mechanisms (hemodynamic effect, thrombosis, artery to artery embolization). The cerebral artery damage may be isolated or multiple (there may be a parallel and/or serial impairment). The paper is devoted to bilateral hemodynamic significant stenosis of the internal carotid artery (ICA). Atherosclerosis can be detected randomly especially when it is asymptomatic, or more frequently, if the disease course is symptomatic - related to ischemic stroke. There are several therapeutic options in the management of the bilateral ICA atherosclerosis:

1. Medication therapy (antiplatelet therapy, statin treatment, ACE or AT inhibitors),

2. Carotid endarterectomy (CEA) - usually staged treatment, and

3. Endovascular treatment (CAS) - one session or staged treatment.

CEA is standard therapy in the patients with the severe symptomatic stenosis (70\%) (Kernan et al. 2014). There are not still clear recommendations in the case of bilateral severe carotid artery stenosis, however endovascular treatment is one from the possible therapeutic choices. Similarly it is not clear, if it is safer to perform staged, or one session treatment. Nowadays it is quite difficult to give a clear answer, because there are only limited data from the clinical studies. We would like to present our data and experience with BCAS in our center.

Address for correspond en ce:

MUDr. Štefan Sivák, PhD., Clinic of Neurology, Jessenius Faculty of Medicine in Martin, Comenius University in Bratislava, Kollárova 2, 03659 Martin, Slovak Republic;

e-mail:sivakste@gmail.com 


\section{MATERIAL AND METHODS}

From 95 patients, who underwent endovascular treatment in our center, we selected patients where BCAS was performed. The single operator did all endovascular procedures. Patients had confirmation of the bilateral hemodynamic severe stenosis of the ICA $\geq 70 \%$ according NASCET) with digital subtraction angiography (DSA). Before procedure CT and/or MRI was performed. Indication for the procedure was done by consensus of neurologist, invasive radiologist, and vascular surgeon. Symptomatic stenosis was defined clinically (presence of TIA or stroke), or radiologically (stroke on CT/MRI). Timing of the procedure was at least 4 weeks after stroke. None of patients had restenosis after previous intervention. In all patients comorbidities such arterial hypertension, ischemic heart disease, diabetes mellitus, smoking, and hyperlipidemia, previous TIA or stroke were analyzed. Similarly any complications during procedure and after 30 days post procedurally were analyzed. Hypotension was defined as systolic blood pressure decrease below $90 \mathrm{~mm} \mathrm{Hg}$ or diastolic blood pressure decrease below $60 \mathrm{~mm} \mathrm{Hg}$. Bradycardia was defined as heart rate frequency less than 60 beats/min. Follow up of the patients was performed 7 days, 1, 3, 6, and 12 month after procedure. Possible restenosis was evaluated with ultrasound in previously mentioned intervals. Main ultrasonography criteria were defined as a presence of the complete or partial thrombosis or other in-stent stenosis.

All patients used dual antiplatelet therapy (acetylsalicylic acid $100 \mathrm{mg}$ and clopidogrel $75 \mathrm{mg}$ or ticlopidin $2 \times 250 \mathrm{mg}$ ) at least 3 days before procedure. The procedures were done in standard conditions in local anesthesia, and the transfemoral approach was used in all the patients. Anesthesiologist was present during all procedures, however, all BCAS were performed only in local anesthesia. The type of stent and filter was chosen according to the type of stenosis and vessel tortuosity by the interventional radiologist. Decision what side will be treated initially was based on stenosis severity, where more severe stenosis was performed initially.

\section{RESULTS}

From the total number 95 patients who underwent CAS, nine patients $(8.6 \%)$ meet inclusion criteria, and were enrolled in the clinical study. The study included 8 males and 1

Table 1. Risk factors and initial NIHSS

\begin{tabular}{|l|l|l|l|l|l|l|l|}
\hline $\begin{array}{l}\text { Patient } \\
\text { No/Gender/Age }\end{array}$ & AH & ICD & $\begin{array}{l}\text { History of } \\
\text { TIA/Stroke }\end{array}$ & Smoker & $\begin{array}{l}\text { Diabetes } \\
\text { mellitus }\end{array}$ & $\begin{array}{l}\text { Hyperlipi- } \\
\text { demia }\end{array}$ & $\begin{array}{l}\text { Initial } \\
\text { NIHSS }\end{array}$ \\
\hline $\mathbf{1 / m a l e} / \mathbf{7 6}$ & Yes & Yes & No & No & No & No & 0 \\
\hline $\mathbf{2 / m a l e} / 66$ & Yes & Yes & Yes & No & No & Yes & 9 \\
\hline $\mathbf{3 / m a l e / 6 2}$ & Yes & No & No & Yes & No & Yes & 0 \\
\hline $\mathbf{4 / f e m a l e / 7 7}$ & Yes & Yes & Yes & No & No & No & 0 \\
\hline $\mathbf{5 / m a l e / 6 9}$ & Yes & No & Yes & No & No & No & 2 \\
\hline $\mathbf{6 / m a l e} / 68$ & Yes & Yes & Yes & No & No & No & 3 \\
\hline $\mathbf{7 / m a l e / 5 9}$ & Yes & Yes & No & No & Yes & Yes & 0 \\
\hline $\mathbf{8 / m a l e / 6 5}$ & Yes & Yes & No & No & Yes & Yes & 0 \\
\hline $\mathbf{9 / m a l e / 8 3}$ & Yes & Yes & Yes & No & No & No & 0 \\
\hline
\end{tabular}

$\mathrm{AH}=$ arterial hypertension, $\mathrm{ICD}=$ ischemic coronary disease 
female with average age 69 years (range 59-83 years). From selected patients, 5 of them had symptomatic stenosis, 4 had silent infarctions. Risk factors analysis showed that all patients had arterial hypertension, 7 patients ischemic coronary disease, 2 diabetes mellitus, one was smoker, and 4 patients had hyperlipidemia. All patients had normal kidney function. Initial NIHSS was in the most of cases 0 , three patients were scored 9, 2 , or 3 , respectively. The basic characteristics of the patient's group are shown in the Table 1.

Several types of stents and filters were used, depending on the type and character of stenosis. Most frequently was used Sinus-carotid Conical and RX Accunet system. Technical success was achieved in all cases. Detailed characteristics of used systems and degree of stenosis are shown in the Table 2.

Table 2. Types of used stents

\begin{tabular}{|c|c|c|c|c|}
\hline & No & Degree & Type of stent & Type of filter \\
\hline 1 & $\begin{array}{l}\mathrm{L} \\
\mathrm{R}\end{array}$ & $\begin{array}{l}70 \% \text { symptomatic } \\
70 \%\end{array}$ & $\begin{array}{l}\text { Sinus-carotid Conical } \\
\text { Sinus-carotid Conical }\end{array}$ & $\begin{array}{l}\text { Filter Wire } \\
\text { Filter Wire }\end{array}$ \\
\hline 2 & $\begin{array}{l}\mathrm{L} \\
\mathrm{R}\end{array}$ & $\begin{array}{l}90 \% \text { symptomatic } \\
95 \% \text { symptomatic }\end{array}$ & $\begin{array}{l}\text { Sinus-carotid Conical } \\
\text { Sinus-carotid Conical }\end{array}$ & $\begin{array}{l}\text { Filter Wire } \\
\text { Angioguard }\end{array}$ \\
\hline 3 & $\begin{array}{l}\mathrm{L} \\
\mathrm{R}\end{array}$ & $\begin{array}{l}70 \% \text { symptomatic } \\
70 \%\end{array}$ & $\begin{array}{l}\text { Precise RX } \\
\text { Sinus-carotid Conical }\end{array}$ & $\begin{array}{l}\text { Angioguard } \\
\text { Filter Wire EZ }\end{array}$ \\
\hline 4 & $\begin{array}{l}\mathrm{L} \\
\mathrm{R}\end{array}$ & $\begin{array}{l}70 \% \\
80 \% \text { symptomatic }\end{array}$ & $\begin{array}{l}\text { Sinus-carotid Conical } \\
\text { Sinus-carotid Conical }\end{array}$ & $\begin{array}{l}\text { Angioguard XP } \\
\text { Angioguard XP }\end{array}$ \\
\hline 5 & $\begin{array}{l}\mathrm{L} \\
\mathrm{R}\end{array}$ & $\begin{array}{l}90 \% \\
95 \% \text { symptomatic }\end{array}$ & $\begin{array}{l}\text { X-act carotid stent } \\
\text { X-act carotid stent }\end{array}$ & $\begin{array}{l}\text { RX Accunet } \\
\text { RX Accunet }\end{array}$ \\
\hline 6 & $\begin{array}{l}\mathrm{L} \\
\mathrm{R}\end{array}$ & $\begin{array}{l}99 \% \text { symptomatic } \\
99 \%\end{array}$ & $\begin{array}{l}\text { Sinus-carotid Conical } \\
\text { Exponent }\end{array}$ & $\begin{array}{l}\text { Filter Wire EZ } \\
\text { N/A }\end{array}$ \\
\hline 7 & $\begin{array}{l}\mathrm{L} \\
\mathrm{R}\end{array}$ & $\begin{array}{l}80 \% \\
90 \% \text { symptomatic }\end{array}$ & $\begin{array}{l}\text { X-act carotid stent } \\
\text { X-act carotid stent }\end{array}$ & $\begin{array}{l}\text { RX Accunet } \\
\text { RX Accunet }\end{array}$ \\
\hline 8 & $\begin{array}{l}\mathrm{L} \\
\mathrm{R}\end{array}$ & $\begin{array}{l}99 \% \text { symptomatic } \\
90 \%\end{array}$ & $\begin{array}{l}\text { Sinus-carotid Conical } \\
\text { X-act carotid stent }\end{array}$ & $\begin{array}{l}\mathrm{RX} \text { Accunet } \\
\mathrm{RX} \text { Accunet }\end{array}$ \\
\hline 9 & $\begin{array}{l}\mathrm{L} \\
\mathrm{R}\end{array}$ & $\begin{array}{l}80 \% \\
90 \% \text { symptomatic }\end{array}$ & $\begin{array}{l}\text { X-act carotid stent } \\
\text { X-act carotid stent }\end{array}$ & $\begin{array}{l}\text { RX Accunet } \\
\text { RX Accunet }\end{array}$ \\
\hline
\end{tabular}

From all complications, the most frequent was hypotension alone or combined with bradycardia $(n=7)$. In BCAS group we didn't found TIA, minor stroke, stroke, myocardial infarction. One patient died - patient number 9 after 12 days post procedurally because of malignant arrhythmia. Ultrasound follow-up showed no restenosis in all BCAS patients. Patient number 6 had periprocedural filter occlusion, and patient number 9 had occlusion of common and superficial femoral artery. All complications are shown in the Table 3. 
Table 3. Complications rate

\begin{tabular}{|c|c|}
\hline Patient No & Complication \\
\hline 1 & Hypotension \\
\hline 2 & Hypotension \\
\hline 3 & Hypotension, Bradycardia \\
\hline 4 & Hypotension \\
\hline 5 & Hypotension \\
\hline 6 & Hypotension, Filter occlusion \\
\hline 7 & Hypotension \\
\hline 8 & No complications \\
\hline 9 & $\begin{array}{l}\text { Occlusion of common }+ \text { superficial femoral artery, Death on malignant } \\
\text { arrhythmia at day } 12\end{array}$ \\
\hline
\end{tabular}

Table 4. Complication rate in BCAS studies

\begin{tabular}{|l|c|c|c|c|}
\hline Study & $\begin{array}{c}\text { Number of } \\
\text { patients }\end{array}$ & TIA/Stroke & Death & $\begin{array}{c}\text { Hypotension/ } \\
\text { Bradycardia }\end{array}$ \\
\hline Al-Mubarak et al. 1998 & 5 & $0 \%$ & $0 \%$ & N/A \\
\hline Lesley et al. 2003 & 1 & $0 \%$ & $0 \%$ & N/A \\
\hline Chen et al. 2004 & 10 & $0 \%$ & $0 \%$ & N/A \\
\hline Henry et al. 2005 & 17 & $5.8 \%$ & $11.7 \%$ & $44 \%$ \\
\hline Lee et al. 2006 & 27 & $11.1 \%$ & $0 \%$ & $74 \%$ \\
\hline Wang et al. 2008 & 6 & $0 \%$ & $0 \%$ & $16.7 \%$ \\
\hline Liu et al. 2010 & 24 & $8.3 \%$ & $4.1 \%$ & $29.2 \%$ \\
\hline Dong et al. 2012 & 39 & $5.1 \%$ & $2.6 \%$ & $28.2 \%$ \\
\hline Alurkar et al. 2012 & 9 & $0 \%$ & $0 \%$ & $66.7 \%$ \\
\hline
\end{tabular}

\section{DISCUSSION}

The aim of our study was to analyze efficacy and safety of BCAS performed in one session, one center, and by one interventional radiologist. There are only limited similar series published in the literature (shown in the table 4). Bilateral severe carotid artery stenosis is one specific condition, when BCAS presents as one from the possible therapeutic options.

Our study consists of 9 selected patients with BCAS from a total of 95 patients where CAS was performed. General overview of all CAS patients treated in our center was previously published (Zeleňák et al. 2013). 
Hypotension alone or combined with bradycardia is the most frequent complication of CAS. In our unilateral CAS group hypotension and/or bradycardia occurred in $27.9 \%$ cases what was a similar number to that published in literature (Gupta et al. 2005). In the BCAS subgroup we have found significantly increased frequency - 78\% of BCAS patients met this complication. Alurkal et al. (2012) described very similar complication rate in BCAS. In all cases was hypotension and/or bradycardia resolved by the reduction of antihypertensive therapy. No patient had hypoperfusion syndrome or other serious complication related to hypotension and/or bradycardia.

No patient with BCAS had stroke or TIA, or myocardial infarction. One patient died 12 days after procedure, cause of death was ventricular fibrillation - in this case relationship to procedure cannot be fully excluded. It is possible to declare $11.11 \%$ mortality rate, related to procedure what is similar to previously published data ${ }^{1}$. Incidence of severe complications and hypotension and/or bradycardia in the published clinical studies is summarized in the Table 4.

Only limited data are available concerning the therapeutic strategy in the bilateral ICA atherosclerosis with severe stenosis, and it is not known what is more favorable: one session BCAS or staged CAS. Some centers do not prefer one session treatment (BCAS) because of risk of the hypoperfusion syndrome following hypotension and/or bradycardia after bilateral procedure. The side choice of initial treatment is other important question in the case of staged CAS. The decision is based on the degree of stenosis, or presence of stroke (clinically or radiologically defined) in the affected artery territory, or character of atherosclerotic plaque (stable fibrous plaque vs. unstable soft plaque). Other additional conditions can be Willis circle blood flow geometry and the speed of stenosis progression. Another question is the timing of the second procedure in staged CAS. There are several models described with timing of the second procedure from one day to a couple of weeks. Staged procedure is more expensive, more contrast agent is used and the patient receives more X-rays irradiation. One of the potential risks of staged CAS is a stroke occurrence in the time period between the first and second procedures. In the case of BCAS we mention an additional possible risk, and it is the risk of bilateral in-stent thrombosis in predisposed patient (but such case report was not published yet).

The aim of our study was to show our data, where similar types of analysis are not very frequently published. Study is not aimed to favorite BCAS over staged CAS, CEA, or conservative treatment. Study has many limitations mainly because of small patients group during long period of time. This limitation does not allow to make definite conclusions about its safety of efficacy, and meta-analyses of all published data are necessary.

\section{CONCLUSION}

Because of limited data it is not possible to make any clear conclusions or recommendations from the results of our study. Our data shows that probably BCAS appears to be safe and effective way in the treatment of bilateral carotid artery stenosis in high-risk population. Despite that many centers do not perform BCAS and prefer staged CAS or CEA. This is the first kind of such analysis from Slovakia. Our results are consistent with previously published data. Larger clinical studies are needed.

\section{REFERENCES}

1. Al-Mubarak, N., Colombo, A., Gaines, P. A., Iyer, S. S., Corvaja, N., Cleveland, T. J., et al. (2002): Multicenter evaluation of carotid artery stenting with a filter protection system. J Am Coll Cardiol 39, 841-846. 
2. Alurkar, A., Karanam, L. P., Nayak, S., Oak, S. (2012): Simultaneous Bilateral Carotid Stenting in a Series of 9 Patients: A Single-Center Experience with Review of Literature. J Clin Imaging Sci 2, 72-75.

3. Chen, M. S., Bhatt, D. L., Mukherjee, D., Chan, A. W., Roffi, M., Ziada, K. M., et al. (2004): Feasibility of simultaneous bilateral carotid artery stenting. Catheter Cardiovasc Interv 61, 437442.

4. Diehm, N. D., Katzen, B.T., Iyer, S. S., Wither, C. J., Hopkins, N., Kelley, L., et al. (2008): Staged bilateral carotid stenting, an effective strategy in high-risk patients-insights from a prospective multicenter trial. J Vasc Surg 47, 1227-1234.

5. Dong, H., Jiang, X. J., Peng, M., Ji, W., Wu, H. Y., Hui, R. T., Xu, B., Yang, Y. J., Gao, R. L. (2012): Comparison of the safety of simultaneous bilateral carotid artery stenting versus unilateral carotid artery stenting: 30-day and 6-month results. Chin Med J 125(6), 1010-5.

6. Gupta, R., Horowitz, M., Jovin, T. G. (2005): Hemodynamic Instability after Carotid Artery Angioplasty and Stent Placement: A Review of the Literature. Neurosurgical Focus 18(1), e6.

7. Henry, M., Gopalakrishnan, L., Rajagopal, S., Rath, P. C., Henry, I., Michele, H. (2005): Bilateral carotid angioplasty and stenting. Catheter Cardiovasc Interv 64, 275-282.

8. Kernan, W. N., Ovbiagele, B., Black, H. R., Bravata, D. M., Chimowitz, M. I., Ezekowitz, M. D., et al. (2014). Guidelines for the prevention of stroke in patients with stroke and transient ischemic attack a guideline for healthcare professionals from the American Heart Association/American Stroke Association. Stroke, 45(7), 2160-2236.

9. Lee, Y. H., Kim, T. K., Suh, S. I., Kwon, B. J., Lee, T. H., Kwon, O. K., Seol, H. Y. (2006): Simultaneous Bilateral Carotid Stenting under the Circumstance of Neuroprotection Device: A Retrospective Analysis. Interv Neuroradiol 12(2), 141-148.

10. Lesley, W. S., Lazo, A., Kazmierczak, C. D., Wilseck, J. M. (2003): Simultaneous bilateral carotid stenting for postendarterectomy restenosis. Catheter Cardiovasc Interv 58, 147-50.

11. Liu, S., Jung, J. K., Kim, S. M., Lim, H. K., Kwon, H. J., Kim, J. K., et al. (2010): Simultaneous bilateral carotid stenting in high-risk patients. AJNR 31, 1113-1117.

12. Mathur, A., Roubin, G. S., Iyer, S. S., Piamsonboon, C., Liu, M. W., Gomez, C. R., et al. (1998): Predictors of stroke complicating carotid artery stenting. Circulation 97, 1239-1245.

13. Wang, Y. H., Hsieh, H. J., Lee, C. W., Chen, Y. F., Jeng, J. S. (2008) Simultaneous bilateral carotid stenting in one session in high-risk patients. J Neuroimaging 18, 252-255.

14. World Health Organization, "International Society of Hypertension Guidelines for the Management of Hypertension. Guidelines Subcommittee," (1999): Journal of Hypertension, 17(2), 151-183.

15. Zeleňák, K., Nosál, V., Zeleňáková, J., Kurča, E., Šinák, I., Sivák, Š., Poláček, H. (2013): CASComplications Rate and Relation to Risk Factors. Open Journal of Radiology 3(1), 26-32.

Received: January, 26, 2016

Accepted: February, 26, 2016 